\title{
SEBUAH MODEL CUSP CATASTROPHE UNTUK KECERDASAN
}

\author{
Asti Meiza \\ Fakultas Psikologi UIN Sunan Gunung Djati Bandung
}

In this article, we use cusp catastrophe model for analyze the intelligence. Definition of intelligence is restricted by $I Q$ that can be separated to two aspects, those are Concrete-Practice $(C P)$ and Theoretical-Verbal (TV). We will demonstrate that two students of university with the same aspect of intelligence, $C P$, but have different TV will state in different department of a university. We must get the critical point that differentiate the characteristic of one department with the others. Moving from one department to the other caused by the change of TV will occur as a jump. This jump will determined cusp catastrophe model.

Catastrophe theory provides a universal method for the study of all jump transitions, discontinuities, and sudden qualitative changes. Especially in mathematical understanding, catastrophe theory is a part of singularities theory and bifurcation theory.

The samples were the psychological testing, IST, results of 428 ITB's students. The first step is Confirmatory Factor Analysis application to reduce nine psychotest variables to get two control variables that construct cusp catastrophe model. The second step is fitting the model of cusp catastrophe to the data with Cuspfit procedure. As measurement of goodness of fit, Cuspfit procedure uses the Akaike Information Criterion (AIC) and Bayes Information Criterion (BIC). The model with the lowest AIC and BIC is selected.

Keyword : intelligence, catastrophe theory, cusp model, control variables,behaviour variable, confirmatory factor analysis, cuspfit procedure, AIC, BIC.

\section{Latar Belakang dan Landasan Teori}

Teori Kecerdasan

Dalam sejarah perkembangan psikologi, pencarian ukuran kecerdasan yang sempurna mengalami kemajuan dengan cepat. Dimulai dengan penyusunan tes IQ (Intelligence Quotient) oleh Alfred Binet dari Perancis tahun 1900 hingga teori tentang Kecerdasan Majemuk (Multiple Intelligence) yang dikembangkan oleh Howard Gardner dari Amerika Serikat tahun 1986. Jika dalam sudut pandang Binet, orang yang cerdas adalah orang yang mempunyai kemampuan logika matematika yang tinggi, maka dalam sudut pandang Gardner, kecerdasan dibagi menjadi kecerdasan musik, kecerdasaan kinestetis, kecerdasan logika matematika, kecerdasan linguistik, kecerdasan spasial, kecerdasan antar pribadi, dan kecerdasan intra pribadi. Teori kecerdasan lain membagi kecerdasan menjadi kecerdasan intelektual (IQ), kecerdasan emosi (Emotional Quotient/EQ), dan kecerdasan spiritual (Spiritual Quotient/SQ).

Berikut beberapa pendefinisian kecerdasan yang dikemukakan beberapa ahli. Menurut Binet dan Simon, kecerdasan merupakan kemampuan untuk menilai suatu hal dengan baik, mengerti dengan baik, dan 
mengemukakan pendapat dengan baik. Sedangkan menurut Gardner, kecerdasan adalah kemampuan atau keterampilan untuk menyelesaikan masalah atau menggunakan sesuatu yang bernilai dalam tatanan budaya.

\section{Teori Katastrofi}

Secara bahasa, katastrofi berarti perubahan cepat atau mendadak pada permukaan bumi. Pertama kali diperkenalkan oleh Hassler Whitney tahun 1955 dan dikembangkan oleh Rene Thom tahun 1972 dan V.I.Arnold tahun 1979.

Teori katastrofi menjelaskan perubahan kecil yang kontinu pada variabelvariabel kontrol yang dapat mengakibatkan perubahan secara signifikan pada variabel terikatnya. Teori ini pada prinsipnya berkaitan dengan geometri dari sistem persamaan nonlinier. Sistem persamaan nonlinier tersebut dapat dihasilkan dari kondisi kesetimbangan sebuah sistem dinamik. Sistem-sistem ini dapat diklasifikasikan berdasarkan konfigurasi titik-titik kritisnya di posisi kesetimbangan. Jika konfigurasi ini berubah maka secara kualitatif perilaku sistem juga berubah. Selanjutnya istilah sistem yang digunakan mengacu ke sistem persamaan diferensial nonlinier.

\section{Prinsip-prinsip Dasar Teori Katas-trofi}

Pandang suatu sistem (variabel keadaan, $x$ ) yang diatur oleh suatu persamaan potensial $V$ maka $V$ adalah suatu fungsi di ruang manifold $E$ yang mungkin untuk $x$. Diberikan splitting variable, namakan $a$ dan normal variable, namakan $b$. Kedua variabel ini nantinya adalah komponen utama yang diekstraksi dari data. Sedangkan variabel keadaan adalah merupakan aspek yang akan diukur. Dari ketiga variabel ini dapat dibentuk fungsi potensial

$$
V(x ; a, b)=k
$$

Persamaan matematika ini mendefinisikan suatu bentuk di $R^{3}$. Ini bisa dilihat pada gambar 1.

Dalam penelitian ini model katastrofi yang digunakan adalah cusp, model katastrofi yang paling sederhana dan sering digunakan untuk memodelkan perilaku ketakkontinuan (diskontinu).

Terdapat tujuh macam bentuk dasar katastrofi (lihat tabel 1) yang dikemukakan oleh Thom berdasarkan ukuran kesetimbangan (equalibrium) dan geometri manifoldnya dengan codimensi atau variabel kontrol 1 sampai 4 yaitu $a, b, c$, dan $e$. Sedangkan $x$ dan $y$ adalah variabel keadaan.

Cusp adalah model nonlinier yang merupakan suatu persamaan diferensial dengan tiga variabel yaitu dua variabel kontrol dan satu variabel keadaan. Model ini dipilih untuk memodelkan komponen kecerdasan yang dalam penelitian ini dibatasi pembagiannya menjadi dua yaitu komponen Praktis-Kongkrit (PK) dan Verbal-Teoretis (VT). Selain itu secara umum kemampuan visualisasi manusia juga terbatas sampai pada tiga dimensi.

Cusp dinyatakan dengan suatu fungsi potensial seperti berikut:

$V(x ; a, b)=\frac{1}{4} x^{4}+\frac{1}{2} b x^{2}+a x=0$ 
dengan

$x \quad$ : variabel keadaan

$a, b \quad$ : variabel kontrol

Misalkan keadaan sistem dinyatakan dalam $x$.

Dalam sudut pandang sistem dinamik, keadaan ini berubah terhadap waktu $t$. Diperoleh suatu persamaan diferensial sebagai berikut:

$$
\frac{d x}{d t}=-\frac{d V(x ; a, b)}{d x}
$$

Sebuah sistem yang mempunyai dinamik seperti persamaan di atas dikatakan suatu sistem dinamik gradien. Jika ruas kanan sama dengan nol maka sistem dikatakan dalam kondisi setimbang. Gambar 1 memperlihatkan perilaku model cusp untuk semua variabel kontrol dan variabel keadaan yang membuat sistem dalam keadaan setimbang di $(0,0,0)$. Titik ini merupakan titik pojok pada proyeksi di bidang bifurkasi. Titik inilah yang disebut cusp.

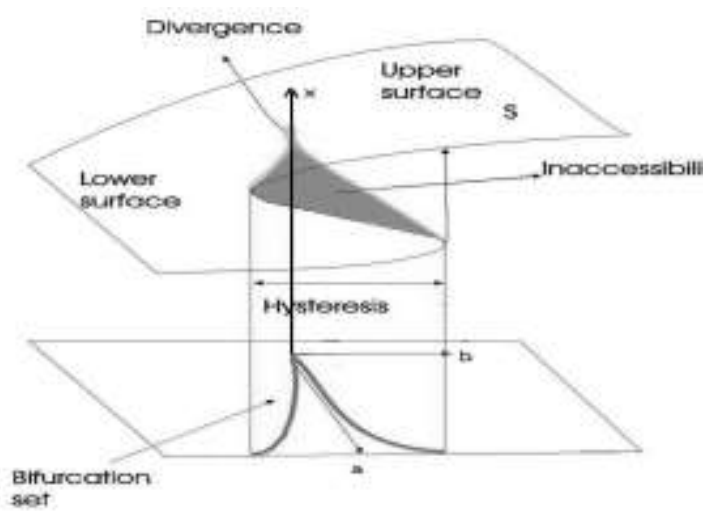

Gambar 1. Proyeksi permukaan di $R^{3}$ ke bidang $R^{2}$.

\section{Model Persamaan Struktur}

Dalam penelitian ini akan dilaku- kan konstruksi model kecerdasan dari sembilan variabel hasil psikotes. Telah diasumsikan bahwa kecerdasan dalam penelitian ini terdiri dari dua aspek yaitu Verbal-Teoretis (VT) dan Praktis-Kongkrit (PK). Untuk itu perlu ditentukan dari sembilan variabel psikotes, variabel mana saja yang mendukung pada aspek VT dan sisanya mendukung aspek PK. Salah satu metode yang dapat digunakan untuk meng- menganalisa hubungan ini adalah Model Persamaan Struktur (Structural Equation Modeling, SEM). SEM mencakup model pengukuran dan model jalur.

Model pengukuran menjelaskan hubungan antara variabel laten dan variabel observasi. Variabel laten adalah variabel yang tidak bisa diukur secara langsung. Di sini variabel laten adalah kecerdasan dengan aspek PK dan VT. Sedangkan variabel observasi adalah variabel yang diperoleh langsung dari pengukuran. Dalam penelitian ini variabel observasinya adalah kesembilan variabel hasil psikotes.

Tabel 1 Tujuh bentuk dasar katastrofi

\begin{tabular}{|c|l|l|}
\hline No. & \multicolumn{1}{|c|}{$\begin{array}{c}\text { Bentuk dasar } \\
\text { katastrofi }\end{array}$} & $\begin{array}{c}\text { Model matematika (fungsi } \\
\text { potensial) } \\
V(x, y ; a, b, c, e)\end{array}$ \\
\hline 1 & Fold & $x^{3}+a x$ \\
\hline 2 & Cusp & $x^{4}+a x^{2}+b x$ \\
\hline 3 & Swallowtail & $x^{5}+a x^{3}+b x^{2}+c x$ \\
\hline 4 & Butterfly & $x^{6}+a x^{4}+b x^{3}+c x^{2}+e x$ \\
\hline 5 & Elliptic umbilic & $\frac{1}{3} x^{3}-x y^{2}+a\left(x^{2}+y^{2}\right)+b x+c y$ \\
\hline 6 & Hyperbolic umbilic & $x^{3}+y^{3}+a x y+b x+c y$ \\
\hline 7 & Parabolic umbilic & $x^{2} y+y^{4}+a x^{2}+b y^{2}+c x+e y$ \\
\hline
\end{tabular}

\section{Model Pengukuran}

Model pengukuran dinyatakan dalam persamaan matematika. Untuk menguji model pengukuran yang diperoleh, digunakan Analisis Faktor Konfirmatori. Akan dilihat apakah model pengukuran untuk IQ tersebut sesuai atau fit dengan data dan karakteristik 
apa saja yang betul-betul mendukung pada kedua aspek IQ tersebut. Model jalur menjelaskan hubung- an sebab akibat antar variabel laten. Jadi di sini akan dilihat hubungan antara kecerdasan dengan kedua aspeknya.

\section{Manfaat dan Tujuan Penelitian}

Dalam penelitian ini, sistem dinamik yang akan dibahas dibangun oleh variabelvariabel kontrol yang akan memberikan dua kecerdasan yang

berbeda. Kecerdasan di sini diasumsikan dibangun oleh dua variabel kontrol yaitu aspek Praktis-Kongkrit (PK) dan aspek VerbalTeoretis (VT) serta satu variabel terikat yang dipandang se- bagai perilaku (behavior) yang diamati. Sedangkan definisi kecerdasan hanya dibatasi pada IQ karena tidak diperoleh data untuk EQ dan SQ.

Pemilihan jurusan di perguruan tinggi selama ini hanya menggunakan kemampuan akademik sebagai satu-satunya komponen seleksi. Sedangkan minat dan bakat tidak diperhitungkan. Ini sering menyebabkan 'kemandegan' studi akibat merasa 'salah jurusan'. Dari hasil penelitian ini, diharapkan tes psikologi bisa dijadikan komponen seleksi atau untuk menempatkan mahasiswa sesuai minat dan bakat yang dipandang sebagai karakteristik kecerdasan..

Penelitian ini diilhami dari tulisan Fitting Cusp Catastrophe dari Molenaar dan van der Maas yang dipublikasikan tahun 2001 dan Sudden Transition in Attitudes dari van der Maas, Kolstein, dan Pligt yang dipublikasikan tahun 2003.

\section{Kerangka Berpikir}

Penelitian ini dilakukan untuk membentuk suatu model persamaan struktur dari aspek-aspek pendukung kecerdasan yang variabel-variabelnya diperoleh dari penerapan metode Ana-lisis Faktor pada sekelompok matrik hasil pengukuran kecerdasan (hasil tes psikologi).

Berikutnya penerapan metode uji kecocokan model pada semua kelompok data untuk mengetahui apakah kelompok-kelompok data yang dipunyai sesuai dengan model kecerdasan yang dibentuk.

Selanjutnya metode uji model juga diterapkan pada kombinasi dua kelompok data untuk mengetahui apakah bias dianalisa dengan persamaan cusp catastrophe. Terakhir menentukan lokasi bifurkasi pada kelompok data yang memenuhi model cusp catastrophe.

\section{Rumusan Permasalahan}

Penelitian ini membahas sistem dinamik yang dibangun oleh variabel-variabel kontrol yang membangun suatu kecerdasan. Kecerdasan di sini diasumsikan dibangun oleh dua va-riabel kontrol dan satu variabel terikat yang dipandang sebagai perilaku (behavior) yang diamati. Perubahan kecil pada variabel kontrol akan membawa satu individu berpindah dari suatu jenis kecerdasan ke jenis kecerdasan yang lain.

Selain beberapa asumsi yang dijelaskan dalam latar belakang, asumsi lain 
yang membatasi penelitian ini adalah tes psikologi yang digunakan dipandang dapat menjaring aspek-aspek kecerdasan maupun aspek-aspek psikologis yang terkait. Terakhir, in-dividu yang diukur dipandang hanya memiliki satu jenis kecerdasan saja walaupun Gardner menyebutkan tidak tertutup kemungkinan untuk satu individu memiliki sekaligus lebih dari satu jenis kecerdasan.

\section{Metode Penelitian}

Partisipan penelitian ini adalah mahasiswa ITB angkatan 2005 seba-nyak 428 orang yang terdiri dari 5 program studi (prodi). Perinciannya.

Tabel 2 Banyaknya sampel

\begin{tabular}{|c|l|l|}
\hline & Program Studi & Sampel \\
\hline 1. & Teknik Arsitektur & 90 orang \\
2. & Teknik Elektro & 99 orang \\
3. & Teknik Geologi & 76 orang \\
4. & Desain & 67 orang \\
5. & Kimia & 79 orang \\
\hline
\end{tabular}

Alat ukur kecerdasan yang digunakan dalam penelitian ini adalah Intelligenz Struktur Test (IST) yang dikembangkan Rudolf Amthauer (Jerman,1922). Tes ini terdiri dari sembilan bagian yang masing-masing mengukur aspek kecerdasan seperti terlihat pada tabel 3.

Seperti umumnya tes kecerdasan, IST juga mempunyai prosedur skoring yang distandarkan pada tingkat usia. Lebih rinci bisa dilihat pada sumber tabel.

Pengolahan data dalam penelitian ini menggunakan program LInear Structural
RELation (LISREL) versi 8.5. Kemudian dilakukan uji kecocokan model. Ada dua uji kecocokan model yaitu uji model persamaan struktur dengan uji Chi-Square dan uji model persamaan cusp catastrophe dengan Cuspfit procedure yang bisa diperoleh bebas di internet.

\section{Uji Model}

Model pengukuran sudah di-bicarakan di atas. Di sini akan dibicarakan uji kecocokannya. Kesesuaian antara model pengukuran yang diperoleh dengan data yang dipunyai diuji dengan dua cara yaitu uji ChiSquare dan uji model Cusp.

\section{Uji Chi-Square}

Uji Chi-Square didasarkan pada hipotesis berikut:

$H_{0}$ : model sesuai dengan data

$H_{1}$ : model tidak sesuai dengan data

Dengan tingkat signifikansi $\alpha$ jika $p_{\text {value }} \geq \alpha$ maka $H_{0}$ diterima. Artinya model sesuai dengan data.

\section{Analisis Faktor}

Analisis Faktor (AF) diperkenalkan oleh Spearman tahun 1904. Metode ini digunakan untuk menen-tukan himpunan faktor yang dianggap mewakili sejumlah variabel yang diukur. Faktor-faktor ini menjelaskan va-riansi dari variabel-variabel yang di-wakilinya.

Ada dua pendekatan pada analisis faktor yaitu Analisis Faktor Konfir-matori (AFK) dan Analisis Faktor Eks-ploratori (AFE). 
Pendekatan AFK dilakukan jika variabelvariabel sudah dipilih untuk diwakilkan pada faktor tertentu. Sedangkan pendekatan AFE dilakukan jika belum diketahui struktur model yang mengatur hubungan variabel dengan alternatif faktor. Hal ini bisa ditentukan dengan program LISREL. Jadi dari awal sudah dibe-baskan pada komputer untuk memilih faktor-faktor pendukung kepada satu variabel.

Dalam penelitian ini tidak dispesifikkan untuk menggunakan salah satu pendekatan. Dari awal telah ditentukan jumlah faktor yang diperlu-kan dengan mengkonstruksi model cusp yang memiliki dua variabel kon-trol. Tapi walaupun demikian, tidak di-tentukan faktor-faktor pendukung dari masing-masing variabel kontrol. Jadi pendekatan AFK dan AFE sekaligus bisa digunakan di sini.

Tabel 3 Subtes IST

\begin{tabular}{|c|c|c|}
\hline No. & Subtes & Aspek kecerdasan yang diukur \\
\hline 1 & Satzerganzung (SE) & $\begin{array}{l}\text { Pembentukan keputusan } \\
\text { dan kemampuan berpikir mandiri }\end{array}$ \\
\hline 2 & Wortauswahl (WA) & $\begin{array}{l}\text { Mengerti bahasa dan berpikir verbal } \\
\text { serta kemampuan berempati }\end{array}$ \\
\hline 3 & Analogien (AN) & $\begin{array}{l}\text { Daya mengkombinasikan dan } \\
\text { kelincahan berpikir }\end{array}$ \\
\hline 4 & $\begin{array}{l}\text { Gemeinsamkeiten } \\
\text { (GE) }\end{array}$ & $\begin{array}{l}\text { Daya abstraksi verbal atau } \\
\text { pembentukan pengertian secara } \\
\text { bahasa }\end{array}$ \\
\hline 5 & $\begin{array}{l}\text { Rechenaufgaben } \\
\text { (RA) }\end{array}$ & Hitung praktis atau daya nalar \\
\hline 6 & Zahlen Reihen (ZR) & Hitung teoretis \\
\hline 7 & $\begin{array}{l}\text { Form Auswahl } \\
\text { (FA) }\end{array}$ & $\begin{array}{lll}\text { Sintesis atau pengambilan } \\
\text { kesimpulan }\end{array}$ \\
\hline 8 & $\begin{array}{l}\text { Wurfel Aufgaben } \\
\text { (WU) }\end{array}$ & Abstraksi ruang \\
\hline 9 & $\begin{array}{l}\text { Merk Auf gaben } \\
\text { (ME) }\end{array}$ & Daya ingat \\
\hline \multicolumn{3}{|c|}{ Sumber tabel: } \\
\hline \multicolumn{2}{|c|}{$\begin{array}{l}\text { Intelligenz Struktur Test } \\
\text { Pouhaupessy, L.F. (1993). }\end{array}$} & (IST) dari Rudolf Amthauer. \\
\hline
\end{tabular}

Pouhaupessy, L.F. (1993).

\section{Cuspfit Procedure}

Diperkenalkan oleh Hartelman tahun 1997. Program ini digunakan un- tuk mencocokkan model cusp. Perhati-kan kembali persamaan (2) di atas. Variabelvariabel kontrol $a$ dan $b$ ditu- lis sebagai fungsi-fungsi linier dari beberapa variabel acak. Untuk mengetahui dimana mulai terjadi bifurkasi (lihat lagi gambar 1), dibuat perbandingan antara bentuk linier dari model cusp dengan model pertumbuhan logistik. Ini dilakukan dengan me-nerapkan statistik Akaike Information Criterion (AIC) dan Bayesian Information Criterion (BIC). Model pertumbuhan logistik dipilih karena juga terdiri dari multivariat dan berbentuk nonlinier serta khususnya perubahan pada variabel keadaannya tidak terjadi sebagai lompatan.

\section{Hasil Penelitian}

Olah data masing-masing prodi dengan LISREL 8.5 memberikan hasil yaitu pertama, statistika deskriptif dan matrik korelasi untuk kesembilan variabel hasil psikotes. Sebagai contoh diambil prodi Teknik Elektro. Hasilnya bisa dilihat pada tabel 4 dan tabel 5 .

Kedua, model persamaan struktur yang memperlihatkan hubungan fak-tor-faktor pendukung kedua variabel laten PK dan VT yang akan dijadikan variabel kontrol pada model cusp ca-tastrophe. Faktor-faktornya diperoleh dengan analisis faktor konfirmatori dua faktor. Masing-masing prodi memiliki persamaan struktur yang berbeda. Karena itu diambil satu persamaan struktur dari prodi tertentu sebagai acuan. 


$$
\begin{aligned}
& \xi_{1}=\lambda_{11} A N+\lambda_{12} Z R \\
& \xi_{2}=\lambda_{21} S E+\lambda_{22} W A+\lambda_{23} G E+ \\
& \quad \lambda_{24} R A+\lambda_{25} F A+\lambda_{26} W U+\lambda_{27} M E
\end{aligned}
$$

Model persamaan struktur ini dipilih karena hasil diagram jalur kelima prodi, komponen AN dan ZR hampir selalu mendukung kepada faktor $\xi_{1}$.

Ketiga, diagram jalur model pengukuran kecerdasan yang diperoleh dari matrik korelasi dan model persamaan struktur.

Sebagai contoh diambil diagram jalur dua faktor untuk prodi Teknik Elektro. Lihat gambar 2.

Keempat, matrik loading factor $\xi_{1}$ dan $\xi_{2}$ yang berisi koefisien bobot dari faktor-faktor pendukung pada mo- del pengukuran.

$$
\xi_{1}=\left[\begin{array}{cc}
1 & 0,27 \\
1 & -0,33 \\
1 & 0,44 \\
1 & 0,22 \\
1 & 0,21
\end{array}\right]
$$

$$
\xi_{2}=\left[\begin{array}{lllllll}
0,17 & 0,22 & 0,29 & 0,22 & 0,89 & 0,65 & 0,47 \\
0,55 & 0,48 & 0,32 & 0,76 & 0,77 & 0,47 & 0,43 \\
0,39 & 0,40 & 0,38 & 0,42 & 0,53 & 0,59 & 0,39 \\
0,42 & 0,15 & 0,40 & 0,54 & 0,85 & 0,63 & 0,32 \\
0,41 & 0,37 & 0,68 & 0,37 & 0,37 & 0,20 & 0,59
\end{array}\right]
$$

dengan $\xi_{1}$ variabel kontrol pertama yaitu aspek Verbal-Teoretis dan $\xi_{2}$ variabel kontrol kedua yaitu aspek Praktis- Kongkrit. Gabungan kedua variabel kontrol ini akan membentuk $\eta$ yaitu IQ.
Tabel 4 Statistika Deskriptif Prodi Elektro

\begin{tabular}{|c|l|l|l|l|l|l|}
\hline & $\begin{array}{l}\text { Sub } \\
\text { Test }\end{array}$ & Mean & St.Deviasi & T-value & Skewness & Kurtosis \\
\hline 1. & SE & 110,162 & 6,266 & 174,935 & $-0,173$ & $-0,858$ \\
2. & WA & 116,939 & 6,644 & 175,132 & $-0,243$ & $-0,355$ \\
3. & AN & 107,273 & 7,870 & 135,625 & 0,013 & $-0,254$ \\
4. & GE & 108,505 & 4,991 & 216,331 & 0,267 & 1,205 \\
5. & RA & 118,545 & 9,754 & 120,921 & $-0,325$ & $-0,274$ \\
6. & ZR & 119,364 & 7,917 & 150,008 & $-0,781$ & $-0,317$ \\
7. & FA & 116,182 & 8,442 & 136,929 & $-0,243$ & $-0,417$ \\
8. & WU & 112,869 & 11,701 & 95,978 & $-0,570$ & 0,153 \\
9. & ME & 116,717 & 7,645 & 151,901 & $-1,027$ & 0,512 \\
\hline
\end{tabular}

Tabel 5 Matrik Korelasi Prodi Elektro

\begin{tabular}{|l|l|l|l|l|l|l|l|l|l|}
\hline $\begin{array}{l}\text { Sub } \\
\text { test }\end{array}$ & SE & WA & AN & GE & RA & ZR & FA & WU & ME \\
\hline SE & 1,00 & & & & & & & & \\
WA & 0,16 & 1,00 & & & & & & & \\
AN & 0,06 & 0,16 & 1,00 & & & & & & \\
GE & 0,16 & 0,24 & $-0,09$ & 1,00 & & & & & \\
RA & 0,28 & 0,23 & $-0,19$ & 0,19 & 1,00 & & & & \\
ZR & 0,15 & 0,25 & 0,44 & 0,24 & 0,35 & 1,00 & & & \\
FA & 0,21 & 0,12 & 0,16 & 0,16 & 0,19 & 0,18 & 1,00 & & \\
WU & 0,16 & 0,20 & 0,25 & 0,21 & 0,19 & 0,33 & 0,39 & 1,00 & \\
ME & 0,12 & 0,19 & 0,05 & 0,17 & 0,19 & 0,18 & 0,19 & 0,22 & 1,00 \\
\hline
\end{tabular}

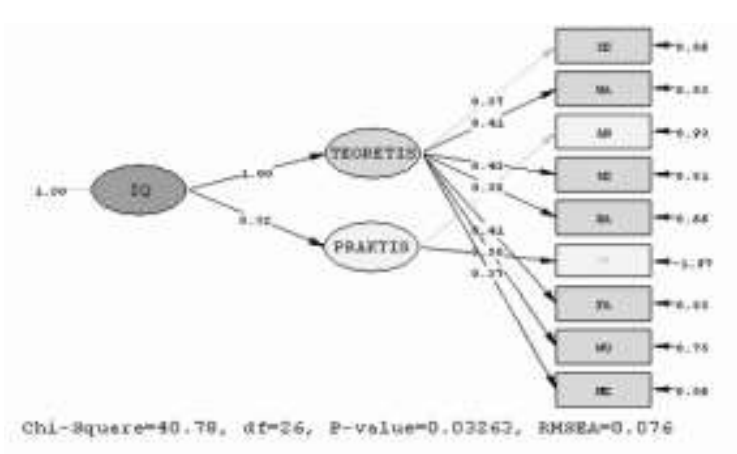

Gambar 2. Diagram Jalur Prodi Elektro

Kelima, prosedur Cuspfit menghasilkan jenis model yang cocok dengan data; linier, cusp, atau logistik. Serta menghasilkan lokasi bifurkasi, artinya koordinat $(x, y)$ yang merupakan titik kesetimbangan. Uji model dilakukan pada kombinasi masing-masing dua prodi. Dari lima prodi diperoleh sepuluh kombinasi. Data berupa nilai kedua variabel 
kontrol $\xi_{1}$ dan $\xi_{2}$ dijadikan input kepada prose-dur ini. Diperoleh hasil uji model untuk kesepuluh kombinasi prodi seperti terlihat di tabel 6.

Data akan mengikuti model cusp catastrophe jika Cuspfit memberikan hasil $A I C<500$ dan $B I C<500$.

Keenam, analisa model kecerdasan. Model cusp catastrophe yang diperoleh diaplikasikan pada kombi-nasi dua prodi. Contoh aplikasi pada prodi Arsitektur dan prodi Kimia dapat dilihat pada gambar 3 . Model ini memperlihatkan dua mahasiswa yang mempunyai aspek PK sama tetapi aspek VT berbeda akan berada pada prodi berbeda. Mahasiswa yang memiliki aspek VT lebih tinggi akan berada pada prodi Arsitektur.

Tabel 6 Hasil Cuspfit Procedure

\begin{tabular}{|c|l|l|l|l|l|}
\hline No. & \multicolumn{1}{|c|}{ Prodi } & $\begin{array}{c}\text { Posisi } \\
\text { lapisan }\end{array}$ & $\begin{array}{r}\text { AIC- } \\
\text { BIC }\end{array}$ & Model & $\begin{array}{c}\text { Lokasi } \\
\text { bifurkasi }\end{array}$ \\
\hline 1. & Arsitektur & Atas & 383,7 & Cusp & $(-0,19,1,94)$ \\
& Desain & Bawah & 395,9 & & \\
\hline 2. & Arsitektur & Bawah & 542,2 & Linier & - \\
\hline 3. & Elektro & Atas & 555,2 & & \\
\hline 4. & Arsitektur & Atas & 473,1 & Cusp & $(-1,16,-1,63)$ \\
& Kimia & Atas & 494,4 & & \\
\hline 5. & Desain & Bawah & 341,5 & Cusp & $(-0,19,2,70)$ \\
& Elektro & Atas & 354,0 & & \\
\hline 6. & Desain & Bawah & 376,0 & Cusp & $(-0,06,1,40)$ \\
& Geologi & Atas & 387,9 & & \\
\hline 7. & Desain & Bawah & 402,0 & Cusp & $(-0,29,0,69)$ \\
& Kimia & Atas & 413,9 & & \\
\hline 8. & Elektro & Atas & 496,6 & Cusp & $(-0,25,-0,42)$ \\
& Geologi & Bawah & 509,2 & linier & \\
\hline 9. & Elektro & Atas & 460,5 & Cusp & $(0,02,1,52)$ \\
& Kimia & Bawah & 473,2 & & \\
\hline 10. & Geologi & Atas & 441,4 & Cusp & $(0,38,-0,65)$ \\
& Kimia & Bawah & 453,6 & & \\
\hline & & & & & \\
\hline & Cusp & $(0,15,8$ \\
\hline
\end{tabular}

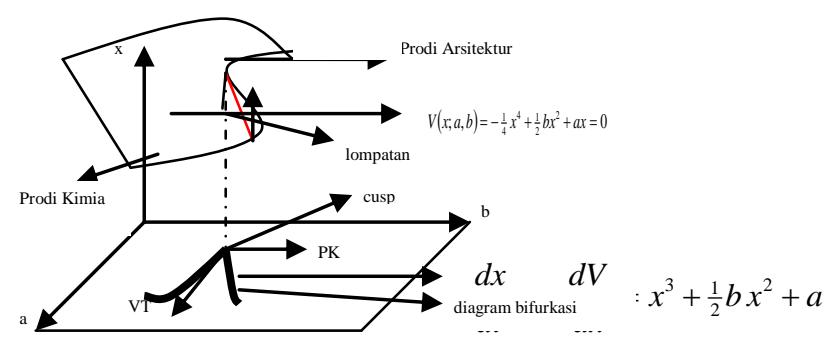

Gambar 3. Model cusp catastrophe

\section{Simpulan dan Saran}

\section{Simpulan}

1. Model pengukuran untuk kecerdasan yang diusulkan tidak dapat diterap- kan pada prodi Desain karena loading factor $\lambda$, untuk variabel AN bernilai negatif. Ini berarti pada prodi Desain, aspek Verbal-Teoretisnya berbeda dengan prodi lain yang didukung oleh variabel $\mathrm{AN}$.

2. Data akan mengikuti model cusp ca tastrophe jika Cuspfit procedure menghasilkan $A I C<500$ dan $B I C<500$.

3. Lokasi bifurkasi antara kombinasi prodi, misal Desain dan Geologi terjadi pada ($0,016,1,40)$ dengan skala 0,89 . Melewati titik bifurkasi ini akan terjadi jump (lompatan) dari lapisan bawah ke lapisan atas. Ini berarti seorang mahasiswa dari prodi Desain jika komponen VT nya bertambah ia akan berpindah ke prodi Geologi.

4. Perbedaan karakteristik tidak terlihat pada kombinasi prodi Elektro dan prodi Arsitektur. Model yang cocok untuk kelompok data ini adalah model linier (lihat tabel 6). Hal ini bisa disebabkan oleh pemilihan program studi tidak sesuai dengan minat dan bakat yang dipandang sebagai karakteristik kecerdasan, tetapi juga dipengaruhi oleh 
faktor-faktor eksternal mahasiswa, misalnya peluang kerja atau status sosial.

\section{Saran}

1. Sesuai perkembangan teori kecerdasan bahwa kecerdasan bukan semata-mata ditentukan oleh aspek IQ (Intelligennce Quotient), disarankan ke depan bisa dilakukan juga pengukuran aspek EQ (Emotional Quotient) dan aspek SQ (Spiritual Quotient). Tentunya dengan menggunakan tes psikologi yang terbaru (bukan lagi IST yang diterbitkan 86 tahun yang lalu, tahun 1922). Ini diharapkan bisa memberikan gambaran yang lebih utuh tentang kecerdasan individu modern ini.

2. Direkomendasikan untuk menggunakan tes psikologi sebagai bagian dari seleksi penerimaan mahasiswa (placement test). Dengan ini diharapkan kejadian 'salah jurusan' karena tidak sesuai dengan minat dan bakat pada mahasiswa yang berakibat prestasi akademik tidak optimal, dapat diminimasi.

\section{Daftar Pustaka}

Arnold, V.I. (1992). Catastrophe Theory. Germany : Springer-Verlag Berlin Heidelberg.

Demazure, M. (2000). Bifurcations and Catastrophes : Geometry of Solutions to Nonlinear Problems. Germany : SpringerVerlag Berlin Heidelberg. du Toit, Mathilda and du Toit, Stephen (2001). Interactive LISREL : User's Guide. USA : Scientific Software International, Inc.

Latuconsina, Roslan (2006). Analisis Model Pengukuran Kinerja Pembelajaran Kalkulus Melalui Metode Confirmatory Factor Analysis. Tesis Master. Bandung : ITB.

Flay, B.R. (2001). Catastrophe Theory in Social Psychology : Some Applications to Attitudes and Social Behavior. Behavioral Science : ProQuest Information and Learning Company.

Fruchter, B. (1954). Introduction to Factor Analysis. Princeton : D.Van Nostrand Company, Inc.

Gilmore, R.(1981). Catastrophe Theory Theory for Scientists and Engineers. New York : John Wiley \& Sons.

Gregory, R.J. (2000). Psychological Testing : History, Principles, and

Applications. Third edition. Boston : Allyn \& Bacon.

Polhaupessy, L.F. (1993). Intelligenz Struktur Test (IST) dari Rudolf Amthauer. Suatu Pengantar. Lecture notes in Department of Psychology UNPAD.

Schumacker, Randall E. and Lomax, Richard G. (1996). A Beginner's Guide to Structural Equation Modeling. New Jersey : Lawrence Erlbaum Associates Publishers.

Sharma, Subhash. (1996). Applied Multivariate Techniques. Canada : John Wiley and Sons, Inc.

Susanto, Bambang. (2005). Perluasan Kriteria Informasi Akaike untuk Skema Multivariat dan Pelabelan Data Anomali. Doctoral dissertation. Bandung : ITB.

Tall, D. (1978). Mathematical Thinking and The Brain. Proceedings of PME 2, 333343.

Tong, H. (1990). Non-linear Time Series : A Dynamical System Ap-proach. New York : Oxford Uni-ver Press, Inc.

van der Maas, H.L.J., Kolstein, R. and van der Plight. (2003). Sudden Transitions in Attitudes. Sociological Methods and Research, 32, 125-152.

Van der Maas, H.L.J., Molenaar, P.C.M. and Wagenmakers. (2004). Fitting the Cusp Catastrophe Model.

http://users.fmg.uva.nl/hvandermass/.Cuspfitpr ogram. 
Psympathic, Vol. I, No.1, 2008: 75 - 84 